\title{
Review on Correlation of Plant Physiology and Breeding for Crop Improvement Strategies
}

\author{
Dejen Bekis* \\ Ethiopian Institute of Agricultural Research, Fogera Agricultural Research Center, Ethiopia
}

*Corresponding Author: Dejen Bekis, Ethiopian Institute of Agricultural Research, Fogera Agricultural Research Center, Ethiopia

\begin{abstract}
Crop physiology is a prerequisite to the effective application of new techniques in plant breeding. The objective of this paper was to examine physiological factors and successful breeding strategies that underlie for yield improvement. Considering for the maximum genetic yield potential of improved varieties to be fully expressed, needs a great pay due attention to crop management practices. The full economic benefits of genetic improvement can never be realized without adequate soil fertility, appropriate planting methods, effective control of weeds and pests and efficient water management. Nothing is good in breeding decisions to be made based on our incomplete knowledge of the biology and ecology of plants. Breeding for higher yield potential is concerned with crop architecture, harvest index, phenology and development within the bounds of a given season and crop management system. Thus, molecular plant biology might finally achieve its glory in plant breeding. Physiological aspects such as; source-sink relationship; effects of light interception and utilization; water use efficiency; transpiration use efficiency; partitioning and harvest index; nutrient use efficiency; biomass, ASI, photosynthesis, leaf (area, size, thickness, index, canopy and angle) and stomatal conductance are crucial for successful crop improvement through breeding strategy. Therefore, it is crucial to review physiological bases to successful breeding strategies for subsequent crop yield increment.
\end{abstract}

Keywords: Breeding-strategy, Crop, Genetic-improvement, Physiology.

\section{INTRODUCTION}

Breeding is frequently referred to as a blend of science and art, as well as an empirical process. The science refers to the routine application of specific genes in conferring disease resistance or environmental adaptation for subsequent yield improvement. The art of breeding refers to the intuition gained by working with germ plasm and the integration of experience with established knowledge about the plants. In other words, nothing is good in breeding decisions to be made based on our incomplete knowledge of the biology and ecology of plants. Physiological understanding adds to the science and as such complements the intuitive knowledge required to conduct good breeding (Reynolds et al, 2001).

Crop physiology is a prerequisite to the effective application of new techniques such as genetic transformation, functional genomics and marker-assisted selection in breeding. Considering for the maximum genetic yield potential of improved varieties to be fully expressed, needs a great pay due attention to crop management practices. Without adequate soil fertility, appropriate planting methods, effective control of weeds and pests, and efficient water management, the full economic benefits of genetic improvement can never be realized (Duvick, 1999; Reynolds et al; 2001; Duvicket al., 2004).

Breeding for higher yield potential is concerned with crop architecture, harvest index, phenology and development within the bounds of a given season and crop management system, have all been optimized, or nearly so in modern production systems. This is where molecular plant biology might finally achieve its glory in plant breeding (Reynolds et al., 2012).

In general, physiology has leading role for crop improvement since nothing substitutes its essence for crop production. An increasing for improvement of physiological aspect can increase the yield potential of the crop by significant folds. Thus, physiology and breeding could be considered as two sides of a coin. However; it is surprising that many breeders have a sceptical attitude towards physiology, and consider that physiology has contributed little to breeding (Pugsley, 1983). According 
to Passioura(1981), a physiologist, also referred to the many 'barren marriages between physiology and breeding.It is therefore, review on physiological bases for successful breeding strategies is very crucial.

\section{Overview of Physiological Basis for Successful Breeding Strategies}

The constant genetic gain for yield of hybrids observed that was a Pioneer in the hybrid ERA set since the mid 1920's. Along with no major changes occurred in yield potential per plant under non-limited conditions. In order to understand historical yield increases, it is essential to consider and understand biomass production and yield formation response to the environmental condition. The total biomass accumulation in crops depends on plant population, the length of the growing season and crop growth rate (Duvicket al., 2010).

However, growth is limited by incomplete canopy cover and low light interception, followed by a linear phase and finally a senescent phase. C4 plants such as maize have higher rates of photosynthesis, resulting in elevated dry matter production rates as compared with $\mathrm{C} 3$ crops (Connor et al., 2011).

In the absence of nutritional and biotic limitations, crop growth rate and biomass accumulation canbe viewed as either light-limited or water-limited, and along with consideration of the fraction of total biomass allocated to grain. As shown in Fig.1, application of physiological framework for breeding can help to predict biomass production and yield formation through the crops life cycle (Hammer et al., 2009).

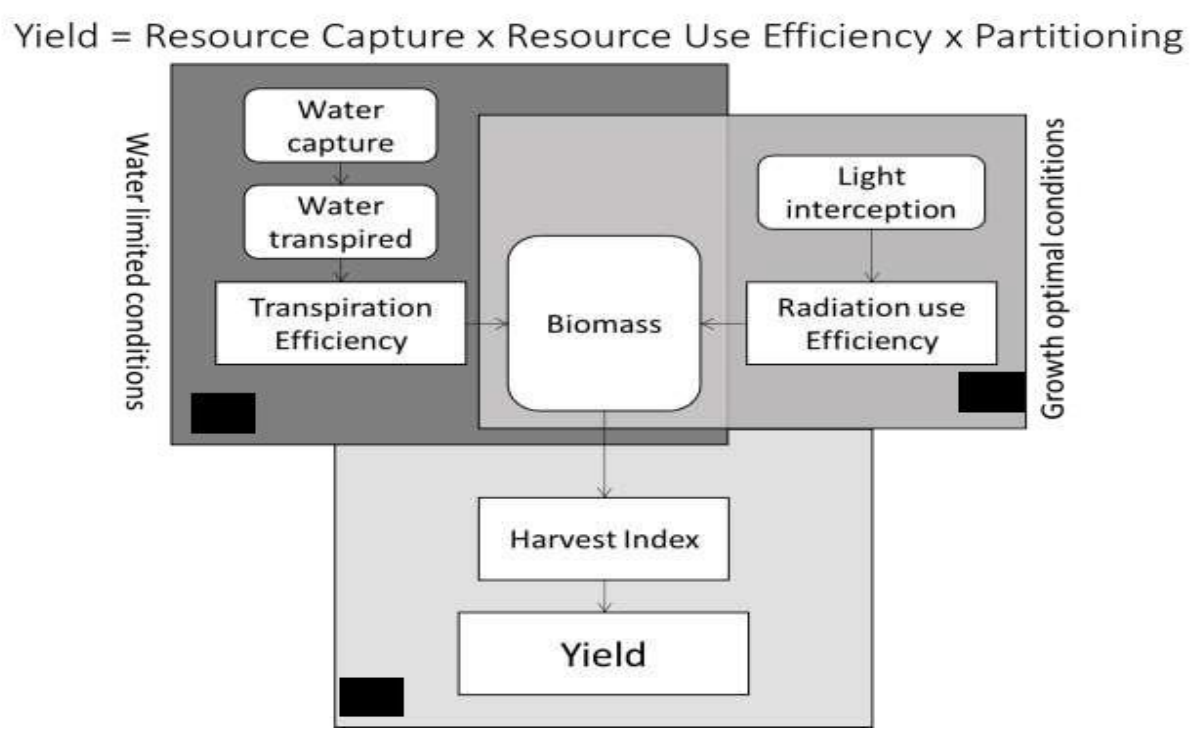

Figure1. The physiological framework for cereal biomass production (Hammer et al., 2009)

The figure is driven by light under optimal growth conditions with no abiotic or biotic limitations. Under water-limited conditions, water capture and the efficiency of water utilization drive biomass production. HI represents the proportion of biomass partitioned to harvestable yield.

Crop growth is depend on available water present and the amount of light the canopy can intercept(Monteith,1969), which is a direct function of leaf area and canopy architecture and the rate at which that radiation is converted to biomass(Gifford et al., 1984; Sinclair et al., 1999). Muchowet al. (1994) found that biomass accumulation was decreased by lower radiation interception in sugar cane. Radiation use efficiency (RUE)is known to vary among species. Kiniryet al. (1989) indicated that mean RUE values for five grain crops based on different studies, with values for rice and sunflower of $2.2 \mathrm{~g} \mathrm{MJ}^{-1}$, wheat and sorghum $2.8 \mathrm{~g} \mathrm{MJ}^{-1}$ and maize $3.5 \mathrm{~g} \mathrm{MJ}^{-1}$. Water productivity is considered as the biomass produced per unit of water transpired has been proposed as a selection criterion to increase yield and gain yield stability under limited water conditions and genetic variation(Hammeret al., 1997).

Yield formation is dependent on the proportion of total biomass that is partitioned to harvestable organs. For the last four decades, increased HI has been associated with progress in development of new varieties of crops such as rice, wheat, and barley, indicating an improvement in grain set via 
shifting (e.g. dwarfing) or remobilizing carbon assimilates from the shoots to the grain (Smith et al., 2010).In general, $60 \%$ of grain yield increment was attributed to genetic improvement whereas $40 \%$ was attributed through improved agronomic practices (Duvick, 1992).

\subsection{Source-Sink Relationship}

Grain yield is the product of accumulating dry matter and allocating a portion of the total aboveground biomass to the grain. The processes influencing DMA are commonly referred to as the "source" components. On the source side, changes in leaf canopy size and architecture account for only a minor portion of the improvement. The majority of the improvement in source capacity is due to visual and functional "stay-green." It is net exporters of assimilates. The processes influencing allocation of dry matter to the grain are referred to as the "sink" component which are net importers of assimilates. In maize, the improvement in sink side is through changes in the relationship between kernel number per plant and plant growth rate during a period bracketing silking. Its improvement has been made through breeding (i) in a closed germ plasm pool stratified into heterotic groups; (ii) through use of a pedigree method of breeding structured to mimic reciprocal recurrent selection and thereby improving both additive and non-additive genetic effects; and (iii) by a gradual increase in plant densities during the hybrid era as the constant source of stress during both inbred line development and hybrid commercialization. Functional stay-green and the sink establishment dynamics still represent opportunities for yield improvements.

It is essential that source and sink should keep in balance. But, abiotic stress may acts to shift source and sink processes out of balance. Excess source capacity, relative to sink capacity, results in other tissues (e.g., leaves, stalks) acting as sinks. Purpling of leaves, sheath tissues, and stalks during the grain-filling period (GFP) are classic symptoms of excess source capacity. Excess sink capacity, relative to source capacity, results in premature senescence of leaves and stalks during the GFP. The improvement in one contributes a simultaneous improvement in the other. One strategy for exploiting these opportunities is to incorporate high plant population density trials into inbred line development programs. Maize breeders during the hybrid era have been extremely successful in making continuous genetic improvement in commercial grain yield that they increased grain yield by six folds which was an equally impressive enhancement in abiotic stress tolerance. In a modern short-season maize hybrid approximately $50 \%$ of the total seasonal dry matter was accumulated by flowering; with the remaining $50 \%$ of the seasonal dry matter being fixed during the GFP(Cliquetet al., 1990; Tollenaaret al., 2004 and LeeandTollenaar, 2007).

\subsection{Physiology and Breeding under Stress Conditions}

Crops were limited to production and productivity potential due to numerous impacts of abiotic and biotic stress factors. Grain yield in maize has been associated with the improvement of maize tolerance to stresses that often occur in the target population of environments (TPE) and to the improvement of resource use efficiencies (Duvicket al., 2004).

The correlated response of genetic gain for yield between well-watered and drought environments, and the selection in a target population of environments where biotic and abiotic challenges including drought are frequent, suggest that multiple physiological mechanisms contributed to the observed genetic improvement of yield. It is plausible that the reduction in interval between anthesis and silking(ASI) and the apparent increase in carbohydrate allocation to reproductive organs could result at least in part from improved plant, kernel and ovule water status(Cooper et al., 2014; Duvick, 2005).

Irrigated yield potential of wheat was reduced from 50 to $90 \%$ by drought in the developing world. At CIMMYT attempts were underway to improve drought tolerance by incorporating stress adaptive traits into empirically selected drought tolerant germ plasm. Current conceptual model of a drought resistant cultivar selection should all encompasses the following traits by including some physiological concern on it: seed size, coleoptile length, early ground cover, pre-anthesis biomass, stem reserves/remobilization, spike photosynthesis, stomata lconductance, osmotic adjustment, accumulation of abscisicacid, heat tolerance, leaf anatomical traits (such as glaucousness, pubescence, rolling, thickness), high tillers and stay green. High stomatal conductance permits leaf cooling through evapotranspiration; this, along with higher leaf chlorophyll content and stay-green, is 
associated with heat tolerance. Recent studies identified high expression of these traits in bank accessions, and both traits showed high levels of heritability under heat stress. As a result, these accessions were crossed into good heat tolerant backgrounds. Leaf traits, such as leaf rolling, leaf thickness, and upright posture, may play similar roles under stress (Reynolds et al., 1999).

\subsection{Genetic Improvement and Physiological Changes in the Hybrid Era}

The best known and most extensively studied set of material is called the "ERA hybrids". The ERA hybrids were developed and released by Pioneer Hi-Bred International from 1930 to 2001 (Duvick, 1997 and Duvicket al., 2004). All of the hybrids were considered to be successful, widely grown hybrids, representative of the elite germ plasm of the decade. Grain yield is not only due to genetic improvement, but also substantial changes to agronomic practices during the last 65 to 70 years period. Starting somewhere in the 1960s commercial fertilizers were used; with increasing $\mathrm{N}$ levels occurring until the mid-1980s.Better weed control was achieved through use of herbicides was first used commercially in 1945 and atrazine was first used commercially in 1965. More uniform distribution of plants within a field was achieved by reducing row widths from $102 \mathrm{~cm}$ to $76 \mathrm{~cm}$ in the mid-1960s to early 1970s ( Troyer, 2004). Earlier maize planting has effectively increased the duration of the growing season and, consequently, the period of time that plants could absorbed incident solar radiation.Finally, plant population densities gradually increased from 30,000 plant ha ${ }^{-1}$ to 79,000 plants ha ${ }^{-1}$ (Crosbieet al., 2006).

In general, the increase in grain yield was due to the interaction between genetics and agronomic practices (Tollenaar and Lee, 2002). To make meaningful comparisons given the genetics $\times$ agronomics interaction, it is important to examine the genotype of agronomic management (i.e., plant population density) that was utilized at the time of release. To fully appreciate the change of physiological attributes during the hybrid era, brief examination of what has not changed during the hybrid era is crucial. Hence; hybrid grain yields have increased, inbred line grain yields have mirrored them, resulting in no significant change in the magnitude of heterosis for grain yield (Duvick, 1999 and Duvicket al., 2004).

The ERA-hybrid studies showed a 2.13 folds increase in grain yield between 1930s and 1990s hybrids. Thus, 2.13 fold increases in ERA hybrid grain yield represents a $113 \%$ improvement in DMA.The increase in DMA (i.e., the "source") can be attributed, in part, to quantifiable changes in light interception due to increased leaf area index (LAI) and changes in light utilization due to more erect upper leaves. Another part of the improvement in DMA was attributable to maintenance of green leaf area and leaf photosynthesis during the GFP. However; it is difficult to quantify directly the portion of the contribution to DMA. The contribution can be estimated, from the difference between the total increase in DMA as increased light interception and canopy architecture (Duvicket al., 2004).

\subsection{Effects of Light Interception and Utilization}

DMA is a function of the duration of the life cycle, and the interception and utilization of incident solar radiation in the cycle. Light interception is primarily driven by leaf area, while light utilization is a function of canopy photosynthesis. Leaf area per plant has remained fairly stable during the hybrid era (Duvick, 1997), but increased plant population density tolerance has effectively increased leaf area index (LAI) from $\sim 2.4 \mathrm{~m}^{2} \mathrm{~m}^{-2}$ for a 1930s hybrid to $\sim 4.8 \mathrm{~m}^{2} \mathrm{~m}^{-2}$ for a 2000 s hybrid. Doubling the LAI from 1930 s to 2000 s hybrids has translated into an approximately $20 \%$ greater light interception (Duvicket al., 2004).

Utilization efficiency of intercepted irradiance at high levels of PPFD increases when leaf angle of the canopy becomes steeper because of the more even distribution of light within the crop canopy and the curvilinear nature of the photosynthesis-light response curve (Long et al., 2006). The benefit of increased leaf angle on canopy photosynthesis can be realized only when light interception is high (i.e., at a high LAI), since a reduction in light interception due to increased leaf angle which is outweigh the benefit of a more even light distribution at a relatively low LAI. Ex. the association between the more erect leaf angle and yield improvement in maize was not a probability of an increased plant density but it came through a result of the combined contribution of increased LAI (i.e., high light interception) and leaf angle increased DMA by 31\% ( Lee and Tollenaar,2007). 


\subsection{Water use Efficiency}

Water stress is one of the main limitations for grain yield improvement of crops in the worldwide (Edmeadesetal., 2001). Grain yield of the nearest maize hybrids was greater than that of older hybrids across water regimes during the GFP. It indicated that grain yield improvements in maize hybrids released between 1980 and 2004 has been associated with increased water use efficiency and not with water uptake (Reynolds etal., 2012).

When soil water exists without limitation, water extraction is controlled by crop demand to the root system (Robertson et al., 1993). Water uptake from the soil varies in time and soil water depletion shifts to deeper soil layers as plants mature (Meinkeet al., 1993).

In both wheat and sorghum genetic variation in root system architecture has been associated with increased water capture at depth. In both cases, there was evidence of association with enhanced adaptation to water limitation and genomic regions controlling root architecture were associated with yield performance in breeding (Mace et al., 2011).

WUE is often defined as the ratio of biomass production to the total amount of water used by a crop. Theoretically, leaf level mechanisms to conserve water such as stomata closure, leaf rolling or movement, should tend to enhance WUE. However, stomatal closure during high periods of evaporative demand may lead to an increase in leaf temperature and consequently increased maintenance respiration (Ludlow et al., 1990).TE better captures the balance of photosynthesis and transpiration at plant level without incorporating the confounding effects of soil evaporation (Tanner et al., 1983).

Bunce(2010) noticed that variability in TE at leaf level between hybrids, but there were no differences between drought tolerant and susceptible genotypes as groups. Recently, however, genetic variability in the effect of VPD on TE has been observed among maize hybrids. This trait, which involves a restricted maximum transpiration rate, has been proposed for selection under water-limited environments because it could allow higher daily transpiration efficiencies and water conservation to improve water status during the period of high demand around flowering (Gholipooret al., 2013 and Messina et al., 2015).

Multiple approaches have been proposed to improve TE or WUE; including alterations in assimilates or photosynthesis at the biochemical level, managing the crop environment to increase transpiration over evaporation, modified stomatal response to environment, and changes in HI(Sinclairet al., 1984). Therefore; as Blum (2009) stated that for higher yield under both drought and well-watered conditions, higher stomatal conductance is required.Thus, Water capturing and use efficiency is very crucial for the genetic improvement in grain yield under drought stress. Transpiration efficiency also has a great role underpinning genetic gain for yield by conferring better water status during the critical period around flowering.

\subsection{Partitioning and Harvest Index}

Dry matter partitioning is the distribution of assimilates among the various parts of the plant. Yield of economically important parts of most crops depends on the translocation of assimilates. The DM of most interest in a crop is the harvestable portion, which is usually in the form of seeds. Most crop physiologists and breeders simply analyses partitioning into seed yield as the product of the total standing above-ground dry matter of a crop at maturity and the HI( Wilson and Reid,1986).

$\mathrm{HI}$ is commonly defined as the ratio of yield to biomass at maturity, depends on the relative proportion of biomass accumulation before and after anthesis and on the ability to mobilize assimilates to grain after anthesis(Ludlow et al., 1990). In Maize grain yield is highly correlated with the total number of kernels per unit of ground area filled at harvest time. Final number of kernels depends on PGR, mainly at the critical sensitive period around flowering time (Andrade et al., 2000), which can be influenced greatly by environmental conditions (e.g. water limitation). Hence, stress and nutrient deficiency around flowering can have a negative effect on ear development and consequently stop the development of kernels. Kernel number has been closely related with the amount of assimilate available at the time of kernel set (Zinselmeieret al., 1999).The reduction in the interval between anthesis and silking (ASI), decrease in the number of plants that do not set ears under high plant densities (i.e. barrenness), and limited change in harvest index (Duvicket al., 2004b). 
Here therefore; there is a direct association between grain yield and ASI which is an indicator of decreased ear growth rate and resource availability per ovule, this lead to genetic gain was determined by increased stress tolerance and resource allocation to reproductive organs (Duvick, 2005b).

Wardlaw (1990) proposed that partitioning or assimilate distribution in plants was controlled by source (supply, limited by the ability to capture and transform radiation), sink (hierarchy of size, position and number of organs), timing of development, and capacity to store and mobilize stored assimilates. Based on results reported in the ERA hybrids, genetic gain is associated with decreased barrenness or increased number of ears per unit of ground area (Hammer et al., 2009a; Duvicket al., 2010). Hammer et al. (2009a) noticed that greater partitioning to the ear during its early development may be due to changes in canopy architecture and that reduced ASI may arise from a lower threshold plant growth rate for ear initiation and silking. There was evidence in sorghum that low soil water content around anthesisdecreased kernel number (sink) and changed partitioning by increasing root to shoot ratio (Van Oosteromet al., 2011). It is plausible, that by enhancing the grain sink, enhanced partitioning to grain. Even though partitioning and harvest index played a fundamental role in the genetic gain in maize yield, till empirical evidence is lacking to support this hypothesis.

\subsection{Nutrient use Efficiency}

The improvement of nutrient use efficiency in cropping systems can be achieved through two main strategies: (1) By adopting more efficient crop management practices (such as nutrient rate, timing, source, and placement); and (2) Through breeding develop more nutrient use efficient cultivars(OrtizMonasterio, 2002).Globally, the nitrogen use efficiency of wheat is only $35 \%$. This low efficiency means that a large proportion of the $\mathrm{N}$ that is applied by farmers is lost, increasing the cost of production and had a negative consequences on the environment. The efficiency of $\mathrm{P}$ fertilizer ranges from around 10 to $30 \%$. Breeding and agronomic management are the two main strategies that can help to improve NUE. Characterizing wheat germ plasm for uptake and utilization efficiency is very important to better understand the mechanisms associated with improved nutrient use efficiency. The breakup of nutrient use efficiency into uptake and utilization should also facilitate the identification of molecular markers that can be later used in a breeding program.Moll et al. (1982) found genetic differences in nitrogen use efficiency among wheat cultivars. This concept was developed by using nitrogen, but it could also essential to judge other nutrients such as phosphorus (Reynolds et al., 2012).

\section{CONCLUSION}

Physiology and breeding jointly required a wide structure with appropriate skill, knowledge and specialization to cover a series of quite distinct operations and responsibilities. Physiology has taken a lion share for all activities of breeding thereby improving quality and yield of the crop as required. How closely the actual yield approaches the genetic potential of a cultivar in a particular situation depends on how well its physiological aspects were matched to the local environment and on the level of agronomic inputs.

Breeding for higher yield potential could be considered with crop architecture, harvest index, phenology and development within the bounds of a given season and crop management system. Yield improvements have occurred mainly through changes to regulatory processes which control the duration of assimilation and the partitioning of assimilate. The regulatory processes seem to offer the best prospects for further improvements, primarily because it exhibit considerable genetic variation in most crops. In general, to be successful in breeding strategy, assessment and incorporate the physiological aspects are crucial. Such as: source-sink relationship; effects of light interception and utilization; water use efficiency; transpiration use efficiency; partitioning and harvest index; nutrient use efficiency; biomass, ASI, photosynthesis, leaf (area, size, thickness, index, canopy and angle) and stomatal conductance.

\section{REFERENCES}

[1] Andrade F. H., Otegui M. a. E. and Vega C. 2000.Intercepted Radiation at Flowering and Kernel Number in Maize.Agron. J. 92: 92-97.

[2] Blum A. 2009. Effective use of water (EUW) and not water-use efficiency (WUE) is the target of crop yield improvement under drought stress. Field Crops Research 112:119-123. 
[3] Bunce J. A. 2010. Leaf Transpiration Efficiency of Some Drought-Resistant Maize Lines. Crop Sci. 50:1409-1413.

[4] Cliquet J. B., Deléens E. and Mariotti A. 1990. C and N mobilization from stalk and leaves during kernel filling by $13 \mathrm{C}$ and $15 \mathrm{~N}$ tracing in ZeamaysL. Plant Physiol. 94:1547-1553.

[5] Connor D. J., Loomis R. S. and Cassman K. G. 2011. Crop Ecology: Productivity and Management in Agricultural Systems. Cambridge University Press, Cambridge.

[6] CooperM.,Gho C., Leafgren R., Tang T. and Messina C. 2014. Breeding drought-tolerant maize hybrids for the US corn-belt Discovery to product.Journal of Experimental Botany. 65: 6191-6204.

[7] Duvick D. N. 1977. Genetic rates of gain in hybrid maize yields during the past 40 years. Maydica 22: 187-196.

[8] Duvick D. N. 2005b.The Contribution of Breeding to Yield Advances in maize (Zea mays L.). pp. 83145.

[9] Duvick D. N., Smith J. and Cooper M. 2004a.Long-term selection in a commercial hybrid maize breeding program. Plant breeding reviews 24:109-152.

[10] Duvick D. N., Smith J. S. C. and Cooper M. 2004b.Long-term selection in a commercial hybrid maize breeding program. In: J. Janick ed. Series; Plant Breeding Reviews, Hoboken, NJ. pp. 109-152.

[11] Duvick D. N., Smith J. S. C. and Cooper M. 2010.Long-Term Selection in a Commercial Hybrid Maize Breeding Program. Plant Breeding Reviews. pp. 109-151.

[12] Duvick D.N. 1992. Genetic contributions to advances in yield of U.S. maize.Maydica 37:69-79.

[13]DuvickD.N., and Cassman K.G. 1999. Post-Green Revolution trends in yield potential of temperate maize in the north-central United States. Crop Sci. 39:1622-1630.

Citation: Dejen Bekis, "Review On Correlation of Plant Physiology and Breeding for Crop Improvement Strategies" International Journal of Research Studies in Agricultural Sciences (IJRSAS), 2020; 6(3), pp. 1-7, http://dx.doi.org/10.20431/2454-6224.0603001

Copyright: (C) 2020 Authors. This is an open-access article distributed under the terms of the Creative Commons Attribution License, which permits unrestricted use, distribution, and reproduction in any medium, provided the original author and source are credited. 